\title{
The Direct Health Facility Financing Impact on Financial Management in Kaliua District Council, Tabora Tanzania
}

\author{
Batamaga Akimu kajuni (Corresponding author)
}

Health Department, Mzumbe University

Kaliua District Council, P.O Box 83, Kaliua-Tabora, Tanzania

E-mail: kajunibatamaga@gmail.com

\author{
Deogratias Faustine Mpenzi \\ School of Public Administration and Management, Mzumbe University \\ P.O Box 1, Mzumbe Morogoro, Tanzania
}

Tel: 255-755-810-450Ｅmail: dmpenzi@mzumbe.ac.tz

\begin{abstract}
Received: October 7, $2020 \quad$ Accepted: January 28, $2020 \quad$ Published: February 28, 2021
doi:10.5296/wjbm.v7i1.17797 URL: https://doi.org/10.5296/wjbm.v7i1.17797
\end{abstract}

\begin{abstract}
This study assessed the implementation of Direct Health Facility Financing (DHFF) on financial management among primary health facilities of Kaliua District Council. The assessment conducted because Kaliua District is the one among 184 councils where the government introduced DHFF; the study adopted case study design whereby, both qualitative and quantitative approaches were used. A structured questionnaire, Interview, FDGs, Documentary review were used in obtaining data which were classified into planning process, rate of fund utilization, adherence to financial management guidelines and perceptions of employees on fund utilization which were administered to 238 respondents who sampled through simple random and purposeful sampling techniques. Data analysed using excel and SPSS for quantitative data and content analysis for qualitative data.

Study revealed that, planning process work in excellent way (72.9\%); utilization capacity of funds disbursed has been acknowledged at 70\%; Fund utilization perceived positively impacting on the quality of health services delivery like availability of medicines and medical equipment in health facilities unlike the time before DHFF. Financial and procurement guidelines to some extent are adhered for about 50\%. However, study observed some
\end{abstract}




\section{Macrothink}

World Journal of Business and Management

ISSN 2377-4622 2021, Vol. 7, No. 1

problems like lack of funds to facilitate HFGCs' activities, late disbursement of funds that affected utilization. Conclusively based on findings, financial management at health facilities is effective as it attributed to significantly positive impacts on general improvement of health services delivery in public primary health facilities.

Keywords: Direct Health Facility Financing (DHFF), Financial management, Primary health facilities 


\section{Introduction}

Health care financing is considered to be one of the important health pillars to hold health services in the world. Other pillars include service delivery, health workforce, health information systems, access to essential medicines, and leadership/ governance. These pillars are termed as health system building blocks (WHO, 2007) Almost half of the world population lack access to basic health care services in which the problems is generally associated with underfunding of health care services which resulted from economic crisis after the world war II (WW II) (WHO, 2007; WHO report, 2010) Such situation led to underfunding of health services delivery that led to shortage of drugs, medical equipment and supplies, deterioration of the physical health infrastructure including electricity supply, water and sanitation at the health care facilities (Wangwe et al., 1998; Cowi et al., 2007) as cited by Mujinja and Kida (2014).

In addressing the above problems like many other countries, Tanzania has gone through several health financing reforms such as Arusha declaration in 1967, which advocated for free health care for all, in 1991 the re-introduction of private health care provision was opted to complement the public sector; In 1993-2004 the introduction of user fees in public facilities to promote equity in accessing health services among the poor; in 1999, a National Health Insurance Fund (NHIF) for public sector workers and in 1996 a Community Health Fund (CHF) (Gemini et al., 2007; MoHSW, 2010; Kolstad \& Lindkvist, 2013 Mujinja \& Kida, 2014). The generated and collected funds by health facilities from user fees, CHF/TIKA premiums, NHIF reimbursement used to be submitted to local government authorities (LGAs) whose vested with power to manage the provision of public services including health services at council level under Local Government Act (LGA Act) of 1982 (Boex, 2015; Kuwawenaruwa et al., 2018 ). In which councils were responsible to plan and control the utilization of fund on behalf health facilities. But literatures still document poor health services delivery due to inadequate fund, shortage of trained health staff, poor communication and transport infrastructure (Boex, 2015; Swere, 2016). As such, the government found it necessary for finances, planning and budgeting to be available and done at facility level since funds disbursed to LGAs for implementing health services always do not match with the requirements. Hence, financial decentralization was needed for providing autonomy to health facilities on financial management and this led to introduction of DHFF to empower facilities to manage funds and procure inputs to deliver health services to their communities so as to increase facility autonomy, transparency, accountability, capacity; and align Public Finance Management (PFM) to ensure good internal controls and financial risk protection and Strengthen basic financial management systems of Planning and budgeting (PlanRep) and Facility Financial Accounting and Reporting System (FFARS) (MOHCDGEC HSSP IV, 2015; URT, 2018). Then it is important to assess the effectiveness of financial management at health facilities.

\subsection{Statement of the Problem}

Improved quality of health services delivery has been a major area of priority in many African countries including Tanzania. This has been affected by various problems including 
weakness in health care financing, shortage of fully trained health staff and poor communication and transport infrastructure. Other problems are shortage of drugs and medical equipment, insufficient funds reaching to health facilities and about $34 \%$ of health facilities having zero star through star rating assessment conducted in 2016. This means generally poor quality of services delivery (World Bank, 1993; World Bank, 1997; WHO, 2000; Mamdani \& Bangser, 2004; NHIF, 2012; MOHCDGEC, 2016; Swere, 2016).

To address above challenges Tanzania in collaboration with health stakeholders introduced DHFF programme in 2016. Under DHFF, funds were directly disbursed from Ministry of Finance and Planning (MoFP) to primary health facilities from financial year 2017/2018. This was done with a conception that DHFF would improve community participation, autonomy, efficiency and effectiveness of available resources and quality of care in sustainable manner (Policy Commitment, 2016; DHFF guide, 2017, Kuwawenaruwa et al., 2018; Kapologwe, 2019).

Studies have documented the positive experience on DHFF programme in improving health services in health facilities (Opwora et al., 2009 and 2010; World Bank, 2013; Waweru et al., 2015). Even in Tanzania, DHFF accounts success to schools. Health facilities have also been managing various sources of fund such as User fee collection, Community Health Funds (CHF), National Health Insurance Fund (NHIF) and used them for running health activities. In addition, facilities implementing Results Based Financing (RBF) in 2017 received 10 million each for rehabilitation. These facilities and communities succeeded to improve the status of health facilities (DHFF guide, 2017). In spite of the success of DHFF as revealed by other scholars, it is not clear about effectiveness of financial management at lower health facilities therefore; this study intended to assess the impact of DHFF on public financial management in public primary health facilities of Kaliua District.

\subsection{Objectives of the Study}

The broad objective of this study was to assess the extent direct health facility financing follow financial management procedures in public primary health facilities of Kaliua District council.

The specific objectives of this study are to:

1) Examine planning procedures work at public primary health facilities of Kaliua District

2) Examine the level of utilization of fund received by public primary health facilities of Kaliua District

3) Explore the level of adherence to financial management guidelines by public primary health facilities of Kaliua District

4) Examine the perception of facility staff, HFGCs, and CHMTs towards fund utilization at facility

\subsection{Research Hypothesis}

H01) There is possibility of effective planning procedures work at health facilities contributes 
to effective financial management

H02) There is possibility of high level of utilization of fund received by health facilities contribute to effective financial management

H03) There is possibility of high level of adherence to financial management guidelines by health facilities contributes to effective financial management

H04) There is significant relationship of good perception of facility staff, HFGCs, CHMTs towards fund utilization at facility and effective financial management

\section{Methodology}

\subsection{Research Design, Area and Study Population}

The research design appropriate and which was chosen is case study design used with both qualitative and quantitative approaches at Kaliua district in Tabora Region. The study area chosen because is one of 184 councils implementing DHFF programme. The target population of the study consists public primary health facilities (health centres and dispensaries) of Kaliua District Council implementing DHFF and their implementers including members of Council Health Management Team (CHMTs), Facility In-charges, facility staff and members of Health Facility Governing Committee- HFGCs (who are community representatives) which totals 238 at the time of assessment.

\subsection{Sample Size and Sampling Procedures}

The researcher obtained a list of health facilities from Health department, a total of 36 out of 40 health facilities were selected for the study obtained by using Yamane formula of 1997 and stratified sampling technique whereby stratification was done using the type of health facilities (that is Health Centres and Dispensaries) as strata. Followed by simple random sampling to select 36 health facilities from the strata; study participants such as facility in-charges, facility staff, HFGCs obtained through simple random sampling technique from 36 facilities and CHMT members were selected using purposeful sampling technique.

\subsection{Measurements}

The instruments used for the study were structured questionnaires, structured interview, focus group discussions and documentary review designed by research team to adopt the specific needs of the study. The instruments were piloted among 2 health facilities before data collection started to ensure reliability and validity and it was found reliable and valid. The questions from the study instruments were categorized into five sections. Section I consists of knowledge on planning, budgeting and planning process work, section II consists of utilization of funds received, section III consists of adherence of financial guidelines among health facilities and section IV consists of perception towards funds utilization.

\subsection{Data Analysis}

Quantitative data analysed using Statistical package for social science (SPSS). Whereby, data from questionnaires were coded and themes from questionnaire named. Then themes from 
questionnaires entered into the SPSS software there after the results generate summarized in tabular form showing numbers in terms of frequencies, sums, percentages and rank orders then the summarized data from tables were analyzed and interpreted. The qualitative data were analysed through thematic content analysis whereby, the conversation recorded from interview and FDGs were transcribed from audio into text typed into computer using Microsoft word then written text were translated from Swahili to English. There after codes initiated and themes searched and reviewed on the basis of codes also the themes defined and named and report produced as per specific objectives.

\subsection{Ethical Issues}

During field work the researcher first informed the respondents about the objectives and benefits of the study and asked respondents' consent before administering the questionnaires, interview and FGD. All participants had an equal chance of being selected in the study, participation was voluntary and Personalities linkage to the data collected from the respondents were avoided, as well as ensuring the confidentiality of data obtained. However, research results and methods were opened to scrutiny by colleagues within the organization and through appropriate report writing.

\section{Presentation of Results}

\subsection{Hypothesis One}

This stated that effective planning procedures work at public primary health facilities contributes to effective financial management

Both knowledge and planning procedures were assessed to see the effectiveness of financial management at public primary health facilities the findings were as follows;-

Table 1. A summary table showing response on level of knowledge in planning and budgeting of employees at health facilities

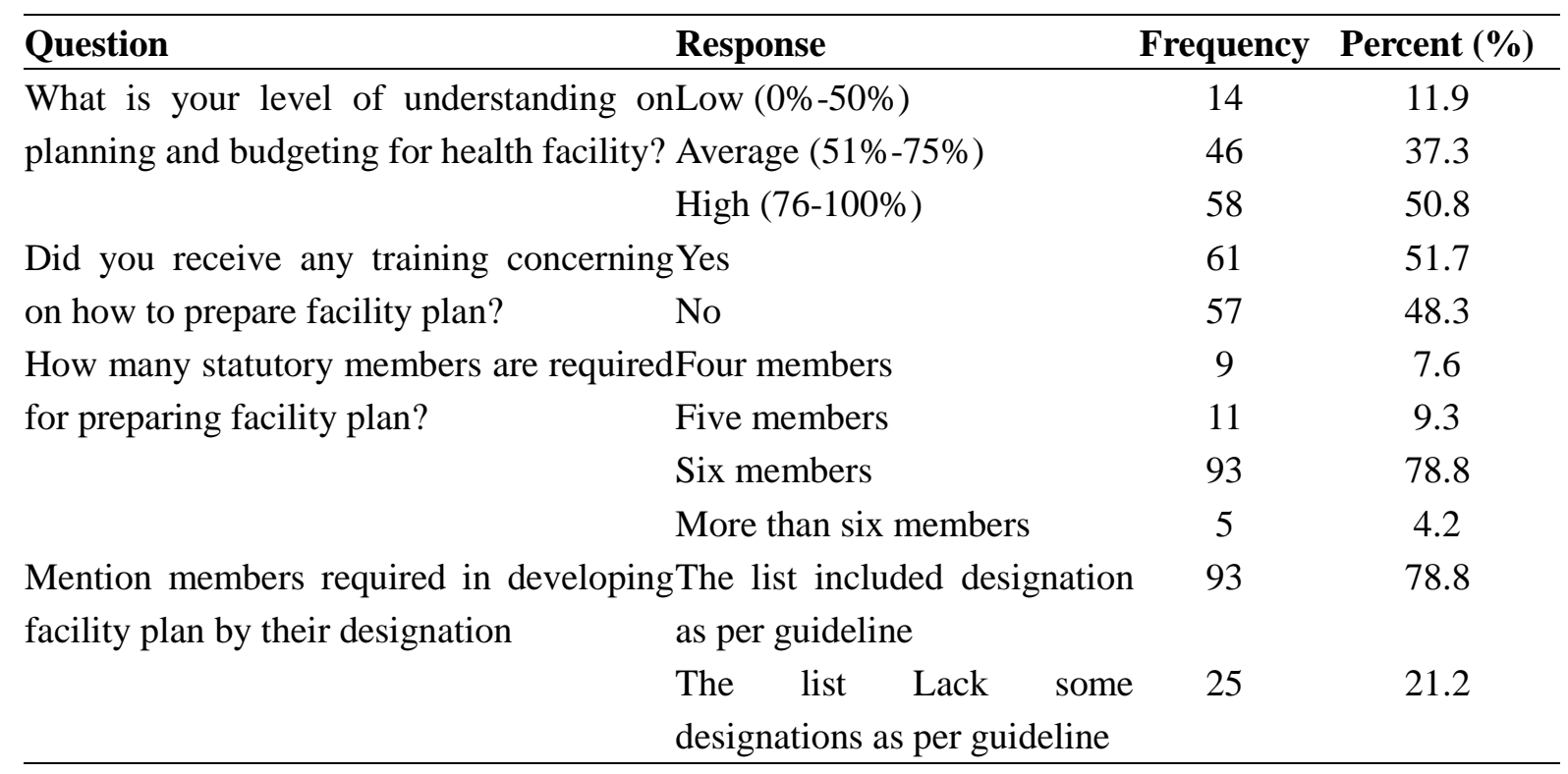


Does the HFGC participate in preparation Yes 2021, Vol. 7, No. 1

of facility plan?

No

118

100

Does the facility have a guideline forYes

0

0

preparing facility annual plan?

No

117

99.2

Source: field data (2020).

Table 2. A summary table showing responses how planning process work at health facilities of Kaliua District council $(\mathrm{N}=118)$

\begin{tabular}{llll}
\hline Question & Response & Frequency & Percent (\%) \\
\hline $\begin{array}{l}\text { What are procedures } \\
\text { should be followed }\end{array}$ & $\begin{array}{l}\text { Mentioned by following systematic } \\
\text { steps as puideline }\end{array}$ & 72.9 \\
when forming annual & $\begin{array}{l}\text { Mentioned without following } \\
\text { systematic steps as per guideline }\end{array}$ & & 27.1 \\
facility plan? & & & \\
\hline
\end{tabular}

Source: Field data (2020).

With regards to table 1 and 2 above shows knowledge and procedures concerning planning and budgeting issues among public primary health facilities staff was averaged to $72 \%$. That, facilities seemed to follow systematic procedures in developing annual facility health plan as per guideline of which the situation indicates effectiveness on financial management therefore hypothesis two is highly supported by the findings

Also during the interview with CHMTs and health workers revealed that planning process used in developing facilities' plan were adhered as per guideline as clarified by one of respondent;

During the second quarter of every financial year DMO's office issuing directive letter to the facility in-charges for starting facility planning and budgeting of next financial year, the facility in-charge provide information to the health committee to submit the views or priorities from community concern issues to be included in facility plan. Then after committee submit the priorities to the team responsible for developing facility plan; the team conduct situational analysis, ranking the problems as per priorities, review of the previous plan to assess its achievement and failure and decide which activities not completed need to proceed on next financial year, then develop the plan as per 14 priority areas of ministry of health, then after plan is being developed is submitted to the HFGC and ward committee for approval then the plan is submitted to the CHMT for approval and compilation (Response: Interview)

\subsection{Hypothesis Two}

Stated that high level of utilization of funds received by primary health facilities attributes to effective financial management.

With regards to the level of utilization of funds received by health facilities majority of the 
respondents $49.2 \%$ and $50 \%$ proved on average and high utilization rate of funds received respectively of which this indicates, health facilities have capacity on utilizing the received funds. However the study revealed that utilization rate was challenged with late received of funds during the mid or/and at the end of financial year as a results most of health facilities end up with remaining of a lot of carryover funds to the next financial year. This was supported by the findings obtained from documentary review on health facilities budget and annual progressive implementation reports for previous financial year 2018-2019 from two sources of funds directly sent to health facilities which are Health sector Basket funds (HSBF) and Result Based Financing (RBF). The findings are displayed in Table 4 and Table 5;-

Table 4. Average percent of health facilities budget vis-à-vis fund received and expenditure for source of Health Sector Basket Fund (HSBF) FY 2018-2019

\begin{tabular}{cccccccc}
\hline No & Facility type & Budget & Receipt & \% & Expenditure & \% & Balance \\
\hline 1 & Health centres & $156,290,814.36$ & $197,004,453.50$ & 133 & $127,671,195.14$ & 65 & $69,333,258.36$ \\
& $(\mathrm{~N}=3)$ & & & & & & \\
2 & $\begin{array}{c}\text { Dispensaries } \\
(\mathrm{N}=33)\end{array}$ & $19,178,620.35$ & $17,416,527.60$ & 94 & $12,384,068.95$ & 75 & $5,032,458.65$ \\
& & & & & & \\
& Total average & $87,734,717$ & $107,210,490.6$ & 114 & $70,027,632.05$ & 70 & $37,182,858.51$ \\
\hline
\end{tabular}

Source: KDC annual Progressive Implementation Report (2018-2019: documentary review).

Table 5. Average percent of health facilities budget vis-à-vis fund received and expenditure for source of Result Based Financing (RBF) FY 2018-2019

\begin{tabular}{|c|c|c|c|c|c|c|c|}
\hline No & Facility type & Budget & Receipt & $\%$ & Expenditure & $\%$ & Balance \\
\hline 1 & $\begin{array}{l}\text { Health centres } \\
\qquad(\mathrm{N}=3)\end{array}$ & $83,441,836.00$ & $40,345,189.24$ & 48 & $24,457,398.56$ & 62 & $15,887,790.68$ \\
\hline \multirow[t]{2}{*}{2} & $\begin{array}{l}\text { Dispensaries } \\
\qquad(\mathrm{N}=33)\end{array}$ & $23,570,941.09$ & $14,347,318.47$ & 61 & $7,162,164.70$ & 50 & $7,185,153.77$ \\
\hline & Total average & $53,506,389$ & $27,346,254$ & 55 & $15,809,782$ & 56 & $11,536,472$ \\
\hline
\end{tabular}

Source: KDC annual Progressive Implementation Report (2018-2019 documentary review).

Data in Table 4 and 5 above show that, health facilities spent a high proportion of $70 \%$ and $56 \%$ of the funds disbursed for HSBF and RBF respectively. These findings indicate that to some extent health facilities have ability to utilize the funds disbursed to them, this ensure the effective financial management in health facilities. However, the above findings from Tables 4 and 5 show a large amount of balance, it was reported such balances was due to late disbursement of funds from central and long procurement process as one the respondents reported that;

DHFF programme is good but the main challenge with it is late disbursement of 
funds which make us fail utilize all funds timely also bureaucracy in procurement process is problem as a result we remain with large amount of money at the end of financial year (Respondent: Interview)

Therefore hypothesis two is highly supported with the findings as they show how health facilities utilize funds

\subsection{Hypothesis Three}

This stated that there is possibility of high level of adherence to financial management guidelines by primary health facilities contributes to effective financial management

Table 6. A summary table showing the level of adherence to financial management guidelines

\begin{tabular}{llll}
\hline Question & Response & Frequency & Percent (\%) \\
\hline $\begin{array}{l}\text { Have you ever received any training of how } \\
\text { to manage public funds through Facility }\end{array}$ & No & 60 & 50.8 \\
$\begin{array}{l}\text { Financing Accounting and Reporting } \\
\text { System (FFARS)? }\end{array}$ & 58 & 49.2 \\
$\begin{array}{l}\text { Does the health facility keep record of } \\
\text { funds in financial documents? }\end{array}$ & No & & \\
$\begin{array}{l}\text { Does health facility reports technical and } \\
\text { financial reports }\end{array}$ & Yes & 102 & 86.4 \\
$\begin{array}{l}\text { Does health facility follows procurement } \\
\text { and stores keeping }\end{array}$ & Yes & 16 & 13.6 \\
Knowledge on financial and procurement & No & 101 & 85.6 \\
documents & financial books) & 17 & 14.4 \\
& Low (confused with & 16 & 85.6 \\
& procurement books) & & 101 \\
\end{tabular}

Source: Field data (2020).

Majority of respondents $50.8 \%$ reported to have been trained on funds management of health facilities also $86.4 \%$ of respondents reported to have knowledge on financial and procurement documents this indicates that financial management is effective as shown in table 6 above also, the hypothesis three is supported by the results. Also the research team checked and reviewed the financial and procurement books, it was found primary health facilities used the books.

\subsection{Hypothesis Four}

This stated that there is significant relationship of good perception of facility staff, HFGCs,CHMTs towards fund utilization at facility and effective financial management. 


\section{Macrothink}

World Journal of Business and Management

ISSN 2377-4622

2021, Vol. 7, No. 1

Table 7. A summary table showing the perception of facility staff, HFGCs, and CHMTs towards fund utilization at facility level

\begin{tabular}{llll}
\hline Question & Response & Frequency & Percent (\%) \\
\hline $\begin{array}{l}\text { Do you think health facilities has } \\
\text { ability to utilize funds received as }\end{array}$ & Yes (facilities are capable) & 89 & 75.4 \\
$\begin{array}{l}\text { per financial guideline } \\
\text { For health facilities to utilize their }\end{array}$ & Yes & 29 & 24.6 \\
$\begin{array}{l}\text { own funds received does quality of } \\
\text { service delivery improved? }\end{array}$ & No & 101 & 85.6 \\
$\begin{array}{l}\text { How do you build capacity of } \\
\text { implementing DHFF activities }\end{array}$ & Training & 17 & 14.4 \\
& On job training & 60 & 51 \\
& Supportive supervision & 23 & 27 \\
& None & 3 & 3 \\
\hline
\end{tabular}

Source: Field data (2020).

With regard to the perceptions of the respondents towards funds utilization at facility level majority of respondents $75.4 \%$ had positive perception that facilities had capacity of utilizing funds. Also the findings supported during interview, the results revealed that majority of respondents perceived positively that health facilities had ability on fund utilization as they follow established guidelines as clarified by one of the respondent that; "...we try our level best to utilize the funds received by following the facility approved plan and adhering to financial and procurement procedures" (Respondent: FDG)

While other participants about $24.6 \%$ perceived negatively on the ability of health facilities to utilize funds received as per guidelines; as one of the respondents reported that;

In my opinions, we cannot manage effective utilization of funds as per guidelines because we have low knowledge in financial and procurement issues, also shortage of account assistants increase heavy workload since we are forced deal with financial issues at the same time we are needed to provide medical services to the clients attending at health facility (Respondent: FDG)

These findings suggest effective management of funds in health facilities that DHFF has achieved the targeted objective of improving quality of services delivery as intended. Also through documentary review the researcher found the photographs of the improved buildings of one of the dispensary after establishment of DHFF and its appearance before DHFF as shown in figure 1 and 2 below; 


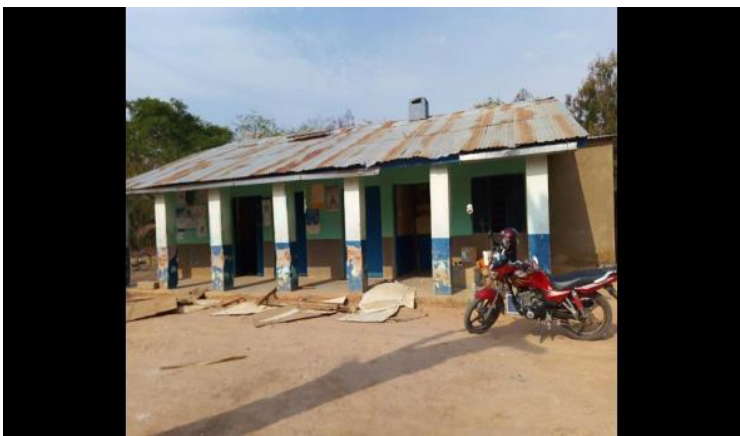

Figure 1. Appearance of Dispensary building within Kaliua District before establishment of DHFF programme

Source: Field data (2020).

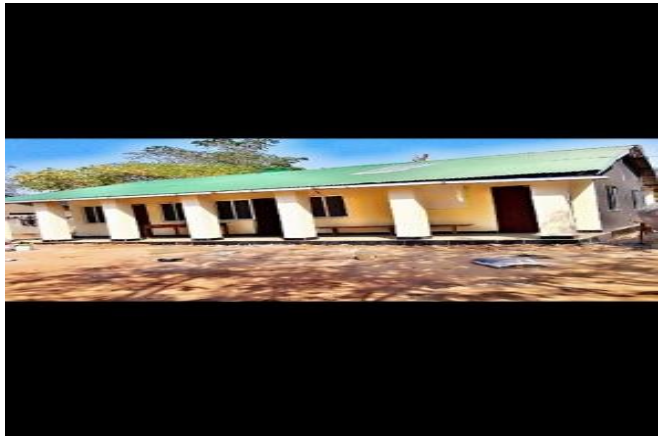

Figure 2. Appearance of Dispensary building within Kaliua District after establishment of DHFF program

Source: Field data (2020).

Therefore hypothesis four is highly supported with the results of study which revealed that respondents had good perception on fund utilization by health facilities as at attributed to the improvement of service delivery that indicates effectiveness of financial management.

\section{Discussion of Findings}

The first hypothesis stated that there is possibility of good planning process work at health facilities contributes to effective financial management facilities. The study revealed primary health to some extent facilities have ability to develop an annual facility health plan as per established minimum requirement for health facility to receive DHFF so as to ensure efficient use resource including funds (URT, 2017). Also these findings are in line with that of UNCEF report (2013), which found that, LGA staff understanding of budget cycle was very high, about $76 \%$ of the respondents were able to explain budget and the stages of budget development. Also there was $99 \%$ availability of planning guideline at health facilities in which the findings are inconsistent with that of Prashanth et al. (2014) stated that, lack of guidelines at local level results to poor implementation of health programmes. In addition Study discovered that, the majority of the respondents $(72.9 \%)$ were able to explain their planning process in accordance with systematic planning procedures as stipulated in the planning guide for health centres and dispensaries (2016) and CCHP guide (2011). The findings imply that, the planning process at health facilities of Kaliua District work in excellent way as they try to adhere to the required procedures established in the guideline the findings align with that of Kigume et al. (2018), conducted a study in 4 districts of Tanzania in which his study found that planning and budgeting process of districts and health facilities follow MoHSW priorities and designs. Therefore with these findings financial management at lower health facilities is accepted to be effective

The second hypothesis stated that there is possibility of high level of utilization of fund received by health facilities contribute to effective financial management. The study found that majority of the respondents $49.2 \%$ and $50 \%$ proved on average and high utilization rate of funds received respectively. However, $100 \%$ of respondents reported on quarterly 
disbursement of funds from central but were lately disbursed especially health basket fund. This reported to affect health facilities in utilization and end up with a huge balance at the end of financial year. These findings align with that of Ayoki, (2008) in Uganda who found that late disbursement of funds for projects made weak project implementation. Also Kenga'ra (2014) in Kenya found delayed receipt of funds by project affects implementation. Also Mapunda (2015) in Ngara District Tanzania found that, late disbursement of funds was a challenge in LGAs. Furthermore, Antony et al. (2017) in Benin found that late disbursement of funds was a limit to the improvement of health services delivery. These findings imply to some extent that, health facilities have ability to utilize funds they received but they face various challenges as reported by majority of respondents included late disbursement of funds from the central government, failure to meet established indicators which determines fund allocation especially for fund source like HBF, RBF, bureaucracy in procurement process, budget constraints, inadequate knowledge on financial and procurement procedures. Therefore second hypothesis is supported by the findings but a big challenge with it seemed to be late disbursement of funds to facilities caused by the government and stakeholders.

Third hypothesis stated that there is possibility of high level of adherence to financial management guidelines by health facilities contributes to effective financial management as the study revealed that, primary health facilities were conversant with financial and procurement books with $85 \%$ presence of necessary financial documents like, cash book, receipt book, cheque book etc. These results are consistent with the requirements established in the Planning guide for health facilities of (2016) and DHFF guide (2017) that health facilities should follow accounting records and stores keeping procedures.

On the other hand, data have shown that, training of DHFF on financial management was inadequate since just $50.8 \%$ of the respondents were trained. These findings are in line with that of Opwora et al. (2010) found out that inadequate training reported as one of challenge in DFF implementation in Kenya. Also Prashanth et al. (2014) reported that, in lower developing countries health programmes are poorly implemented due to inadequate capacity building.

Moreover, through documentary review the study found almost all health facilities had no cheque dispatch book. They provide cheques to their clients without documenting anywhere. These findings agree with that of Opwora et al. (2009) in Kenya who found that there was poor documentation during implementation of DFF. Therefore the hypothesis three is supported with findings that following of financial guidelines and presence of financial documents influence effective financial management of lower health facilities.

Fourth hypothesis stated that there is significant relationship of good perception of facility staff, HFGCs, and CHMTs towards fund utilization at facility and effective financial management. The study found majority of respondents $75 \%$ had generally positive perception on ability to utilize funds as per guideline and approved plans .The findings are align with that of Opwora et al. (2010) found that, sending direct to health facilities perceived to have improved health services also the findings agrees with Regmi et al. (2010) found decentralization was positively perceived associated with increased services access and 
utilization. These findings indicates that DHFF programme assure effective financial management since the utilization of funds by health facilities contributed to the improvement of services. The general perception of the study on the ability of health facilities to utilize their funds received is good since to some extent good performance has been observed which resulted to the improvement of quality of health services at KDC

\section{Conclusion and Recommendation}

Financial management in health facilities perceived to be effective leading to improvement of quality health services delivery. The study recommends for the DHFF to be continued and sustained at lower health facilities as they able to manage funds in which attributed to improvement of service delivery. However, the government and stakeholder are advised to conduct early disbursement of funds to facilitate utilization; also training on accounting and procurement procedure should be developed; and HFGC's activities should be financed to motivate HFGCs on management of funds disbursed to public primary health facilities.

\section{Acknowledgements}

We would like to thank God for his blessings that contribute to the achievement of this manuscript. Also we express our sincere gratitude to Kaliua District Council particularly District Medical Officer for his consent on behalf of District Executive Director to conduct this study. Moreover, we would like to thank all health facilities staff (participants) for their willingness to participate and provide their thoughts; since without them this study could not have been possible

\section{References}

Antony, M., Bertone, M. P., \& Barthes, O. (2017). Exploring implementation practices in results-based financing: the case of the verification in Benin. BMC Health Serv Res., 17(1), 204. https://doi.org/10.1186/s12913-017-2148-9

Ayoki, M. (2008). Causes of slow and low disbursement in donor funded projects in Sub-Saharan Africa: Evidence from Uganda. MPRA Paper No. 87106, posted 02 Jun 2018 14:32 UTC. Retrieved from https://mpra.ub.uni-muenchen.de/87106/

FFARS Manual guide. (2017). Manual on Facility Financial Accounting and Reporting System (FFARS). Bethesda, MD: USAID/Tanzania Public Sector Systems Strengthening Activity, Abt Associates.

Kapologwe, N. A., Kalolo, A., Kibusi, S. M., Chaula, Z., Nswilla, A., Teuscher, T., Aung, K., \& Borghi, J. (2019) Understanding the implementation of Direct Health Facility Financing and its effect on health system performance in Tanzania: A non-controlled before and after mixed method study protocol. Health Research Policy and Systems. https://doi.org/10.1186/s12961-018-0400-3

Kenga'ra Robert. (2014). Effect of Funds Disbursement Procedures on Implementation of Donor Projects in Homabay County, Kenya. Universal Journal of Accounting and Finance, 2(1), 9-23. DOI: 10.13189/ujaf.2014.020102. Retrieved from http://www.hrpub.org 
Kigume, R. et al. (2018). Decentralisation and health services delivery in Tanzania: Analysis of decision space in planning, allocation, and use of financial resources. International Journal Health Planning and Management, 1-15.

Kuwawenaruwa, A. et al. (2018). Bank accounts for public primary health care facilities: Reflections on implementation from three districts in Tanzania. Int J Health Plann Mgmt., 34, e860-e874. https://doi.org/10.1002/hpm.2702

Mapunda, D. S. (2015). Challenges Affecting Implementation of Health Sector Basket Fund activities in the Tanzania Local Government: A case of Ngara district council, Kagera Region, Tanzania. A master's degree dissertation, Mzumbe University. Retrieved from http://scholar.mzumbe.ac.tz/

Masuma, M., \& Maggie, B. (2004). Poor People's Experiences of Health Services in Tanzania. Reproductive Health Matters, 12(24), 138-153. https://doi.org/10.1016/S0968-8080(04)24135-0

Opwora, A., Kabare, M., Molyneux, S., \& Goodman, C. (2010). Direct facility funding as a response to user fee reduction: implementation and perceived impact among Kenyan health centres and dispensaries. Health Policy and Planning, 25(5). 406-18. https://doi.org/10.1093/heapol/czq009

Opwora, A. K.et al. (2009). Implementation and Effects of Direct Facility Funding in Kenya's Health Centres and Dispensaries. Kenya Medical Research Institute Retrieved from http://www.crehs.lshtm.ac.uk/downloads/publications/DFF_report.pdf

Policy Commitment: MOHCDGEC in collaboration with PORALG and Ministry of Finance and Planning (MOFP) will implement effective and efficient direct facility funding to all public health facilities in the FY 2017/18, preceded by a systematic capacity building of planning and financial management to all relevant actors.

Prashanth, N. S., Marchal, B., Kegels, G., \& Criel, B. (2014). Evaluation of Capacity-Building Program of District Health Managers in India: A Contextualized Theoretical Framework. Frontiers in Public Health. https://doi.org/10.3389/fpubh.2014.00089

Regmi, K., Naidoo, J., Pilkington, P. A., \& Greer A. (2010). Decentralization and district health services in Nepal: Understanding the views of service users and service providers. $J$ Public Health (Oxf), 32(3), 406-417. https://doi.org/10.1093/pubmed/fdp116

Swere, K. M. R. (2016). Challenges Hindering the Accessibility of Tanzania's Health Service: A Literature Review. International Journal of Economics and Finance, 8(8). https://doi.org/10.5539/ijef.v8n8p242

UNICEF Tanzania. (2013). Assessment of Government Planning, Budgeting, Monitoring and Reporting in UNICEF supported Local Government Authorities. Final Report March 2013. Dar es salaam Tanzania.

URT. (2011). Comprehensive Council Health Planning (CCHP) Guidelines (4th ed.). 


\section{Macrothink \\ World Journal of Business and Management \\ ISSN 2377-4622 \\ 2021, Vol. 7, No. 1}

Ministry of Health and Social Welfare.

URT. (2016). Guideline for Developing Annual Health Centre and Dispensary Plans. Retrieved from http://www.tzdpg.or.tz/fileadmin/documents/dpg_internal/dpg_working_groups_clusters/clust er_2/health/Key_Sector_Documents/Tanzania_Key_Health_Documents/Final_PLANNING_ TEMPLATE_FOR_HC_and_DISPENSARIES_-_English_Version.pdf

URT. (2017). Direct Health Facility Financing Guide.

Waweru, E. et al. (2015) studied on Tracking implementation and (un)intended consequences: a process evaluation of an innovative peripheral health facility financing mechanism in Kenya. Health Policy and Planning. Retrieved from https://www.rbfhealth.org/sites/rbf/files/Process\%20evaluation\%20of\%20an\%20innovative\% 20health\%20facility\%20financing\%20mechanism.pdf

WHO. (2000). The World health report, 2000. Health systems: improving performance. Geneva: WHO; 2000. Retrieved from http://www.who.int/whr/2000/en/whr00_en.pdf?ua=1

World Bank. (2013). Improving Universal Primary Health Care by Kenya, A Case Study of the Health Sector Services Fund.

\section{Copyright Disclaimer}

Copyright for this article is retained by the author(s), with first publication rights granted to the journal.

This is an open-access article distributed under the terms and conditions of the Creative Commons Attribution license (http://creativecommons.org/licenses/by/3.0/). 